Tropical Journal of Pharmaceutical Research, April 2009; 8 (2): 153-159

(C) Pharmacotherapy Group,

Faculty of Pharmacy, University of Benin

Benin City, 300001 Nigeria.

All rights reserved.

Research Article

Available online at http://www.tjpr.org

\title{
Optimization and Formulation of Orodispersible Tablets of Meloxicam
}

\author{
Jashanjit Singh ${ }^{1 *}$ and Rajmeet Singh ${ }^{2}$ \\ ${ }^{1}$ Department of Pharmaceutics, Swift School of Pharmacy, Village- Gaagar Sarai,Rajpura, ${ }^{2}$ Department of \\ Pharmaceutics ,GHG Khalsa College of Pharmacy, Guru Sar Sadhar, Ludhiana,Punjab, India.
}

\begin{abstract}
Purpose: The objective of this study was to formulate and optimize an orodispersible formulation of meloxicam using a $2^{2}$ factorial design for enhanced bioavailability.

Methods: The tablets were made by non-aqueous wet granulation using crospovidone and mannitol. $A 2^{2}$ factorial design was used to investigate the amount of crospovidone and taste masking, soothening hydrophilic agent (mannitol), as independent variables, and disintegration time as dependent response. Formulated orodispersible tablets were evaluated for weight variation, friability, disintegration time, drug content, wetting time, water absorption ratio and in vitro drug release.

Results: The results show that the presence of a superdisintegrant and mannitol is desirable for orodispersion. All the formulations satisfied the limits of orodispersion with a dispersion time of less than $60 \mathrm{sec}$. For example, formulation $F_{4}$ showed a disintegration time of 32.1 sec, crushing strength of $4.93 \mathrm{~kg} / \mathrm{cm}^{2}$, drug content of $98.5 \%$ and fast drug release rate of 99.5\% within 30 min, as compared with the conventional tablet (49.5\%) .

Conclusion: It is feasible to formulate orodispersible tablets of meloxican with acceptable disintegration time, rapid drug release and good hardness, which could be amenable to replication on an industrial scale.
\end{abstract}

Keywords: Meloxicam, Orodispersion, Crosspovidone, Mannitol, Factorial design, Tablet properties.

*Corresponding author: E-mail- jas_nirman@rediffmail.com; Tel no.: +91-9814819282, +91-1762-653496 Fax no.$+91-175-2300711$ 


\section{Introduction}

Difficulty in swallowing is a common problem of all age groups, especially geriatric and pediatric patients, due to physiological changes associated with these groups. These problems can be solved by development of a novel type of solid dosage form, namely, orodispersible tablet, which disintegrates and dissolves rapidly in saliva without the need of swallowing with drinking water since the tablet is placed in the mouth where it disperses rapidly before swallowing ${ }^{1,2}$.

Clinically, nonsteroidal anti-inflammatory drugs (NSAIDs) are the most frequently prescribed by physicians for inflammatory disorders. Meloxicam [4-hydroxy-2methyl-N(5-methyl-2-thiazolyl)-2H-1,2-benzothiazine-3carboxamide1,1-dioxide], a nonsteroidal antiinflammatory drug, was chosen as a model drug for this study. It is one of the most commonly prescribed NSAIDs for the treatment of various inflammatory conditions such as rheumatoid arthritis, osteoarthritis, low back pain ${ }^{3}$. Although, it has excellent bioavailability $(89 \%)^{4}$, its poor aqueous solubility ${ }^{5}$ makes absorption and dissolution rate-limited, thus delaying onset of action. Consequently, an orodispersible formulation of meloxicam was developed that could enhance the bioavailability and extent of bioabsorption of the drug.

\section{Experimental}

\section{Materials}

Meloxicam was obtained from Siemen Laboratories, Haryana, India while Crosspovidone was supplied by Signet Chemicals, Mumbai, India. Mannitol, colloidal silicone dioxide and spray dried lactose were obtained from Ranbaxy Fine Chemicals Ltd, New Delhi, India. Sodium saccharine and magnesium stearate were obtained from S.D. Fine Chemicals, Mumbai, India. All other solvents used were of analytical grade.

\section{Methods}

\section{Experimental design}

The $2^{2}$ factorial design ${ }^{6}$ was implemented for the optimization of meloxicam orodispersible tablet. The dependent response measured was disintegration time. Two independent factors - the concentration of crospovidone and concentration of mannitol - were set at two different levels. High and low levels of each factor were coded +1 and -1 , respectively (Table 1 ).

Table 1: Experimental design $2^{2}$ used for optimization of orodispersible tablets

\begin{tabular}{ccc}
\hline Formulation & $\begin{array}{c}\text { Crospovidone } \\
(\% \mathrm{w} / \mathrm{w})\end{array}$ & $\begin{array}{c}\text { Mannitol } \\
(\% \mathrm{w} / \mathrm{w})\end{array}$ \\
\hline $\mathrm{F}_{1}$ & 2 & 30 \\
$\mathrm{~F}_{2}$ & 5 & 30 \\
$\mathrm{~F}_{3}$ & 2 & 44 \\
$\mathrm{~F}_{4}$ & 5 & 44 \\
\hline
\end{tabular}

\section{Preparation of meloxicam tablets}

Orodispersible tablets of meloxicam were prepared as per the formula given in Table 2. Accurately weighed quantities of meloxicam, mannitol, crospovidone and other excipients were passed through sieve number 10 (as per Indian Pharmacopoeia) ${ }^{7}$ and mixed in a glass mortar. The above blend was granulated with a non-aqueous granulating agent, alcoholic solution of PVP $(10 \% \mathrm{w} / \mathrm{v})$, and passed through a sieve of aperture size, $710 \mu \mathrm{m}$. The granules were air-dried, mixed with $2 \% \mathrm{w} / \mathrm{w}$ colloidal silicone dioxide, and the granules were passed through sieve number 22, (as per Indian Pharmacopoeia) ${ }^{7}$ lubricated with magnesium stearate and compressed using CADMACH SMS25 single punch tablet machine at a fixed compression force of 400 $\mathrm{kgf}$. The mean weight and diameter of the tablets were $100 \mathrm{mg}$ and $8 \mathrm{~mm}$, respectively.

\section{Evaluation of orodispersible tablet}

All the tablets were evaluated for the following parameters: 
Singh \& Singh

Table 2: Composition of orodispersible tablets of meloxicam

\begin{tabular}{lcccc}
\hline \multirow{2}{*}{ Ingredients(mg/tablet) } & \multicolumn{4}{c}{ Formulations } \\
\cline { 2 - 5 } & $\mathrm{F}_{1}$ & $\mathrm{~F}_{2}$ & $\mathrm{~F}_{3}$ & $\mathrm{~F}_{4}$ \\
\hline Meloxicam & 7.5 & 7.5 & 7.5 & 7.5 \\
Crospovidone $^{*}$ & 2 & 5 & 2 & 5 \\
Mannitol* $_{\text {Sodium saccharine }}$ & 30 & 30 & 44 & 44 \\
Colloidal silicone dioxide $_{\text {Magnesium stearate }}$ & 1 & 1 & 1 & 1 \\
Spray dried lactose & 2 & 2 & 2 & 2 \\
\hline
\end{tabular}

${ }^{*}$ As per experimental design.

\section{Weight variation}

Twenty tablets were randomly selected from each batch and individually weighed. The average weight of these selected tablets was calculated.

\section{Friability}

Tablet friability $^{8}$ was measured using a ROCHE friabilator (USP) at $25 \mathrm{rpm}$ for $4 \mathrm{~min}$. The weight of twenty tablets before and after completion of the test was recorded and friability was calculated by the following formula:

Percentage friability $=($ initial weight-final weight/initial weight $) \times 100$

\section{Disintegration time}

Three tablets per batch were evaluated for disintegration time by employing a modified dissolution apparatus ${ }^{9}$. Instead of the disintegration apparatus described in JP XII, a modified dissolution apparatus (JP XII paddle method) was employed. Water $(900 \mathrm{ml})$, maintained at $37 \pm 0.5{ }^{\circ} \mathrm{C}$ was stirred with a paddle at $100 \mathrm{rpm}$. Disintegration time was recorded when all the fragments of the disintegrated tablet passed through the screen of the basket.

\section{Crushing strength}

Tablet crushing strength, which is the force required to break the tablet, was measured with a Pfizer tablet hardness tester. The hardness (crushing strength) of three tablets per batch was determined and mean taken.

\section{Percentage drug content}

Drug content was determined by taking randomly ten tablets per batch. An amount equivalent to $10 \mathrm{mg}$ meloxicam was dissolved in methanol, suitably diluted with $0.1 \mathrm{~N} \mathrm{HCL}$ and filtered. The absorbance of the solution was measured spectrophotometrically against the blank $(0.1 \mathrm{~N} \mathrm{HCl})$ at $354 \mathrm{~nm}$ using a U.V.spectrophotometer (Shimazdu-1700, Japan)

\section{Kinetic digital images}

One tablet of the selected formulation was placed in a glass full of water (see Figure 1) and the dispersion process was recorded, without agitation, and kinetic digital images were taken with a 7.2 mega pixel camera (Sony- DSC-W55, Japan).

\section{Wetting time and water absorption ratio}

The wetting time of the tablet was measured by placing five circular tissue papers $(10 \mathrm{~cm}$ in diameter) in a Petri dish of $10 \mathrm{~cm}$ diameter. Water $(10 \mathrm{ml})$ containing methylene blue $(0.1 \% \mathrm{w} / \mathrm{v})$ was added to the Petri dish. A tablet was carefully placed on the surface of the tissue paper and the time required for the dye to reach the upper surface of the tablet was recorded as wetting time. The measurements were carried out in triplicate. Water 


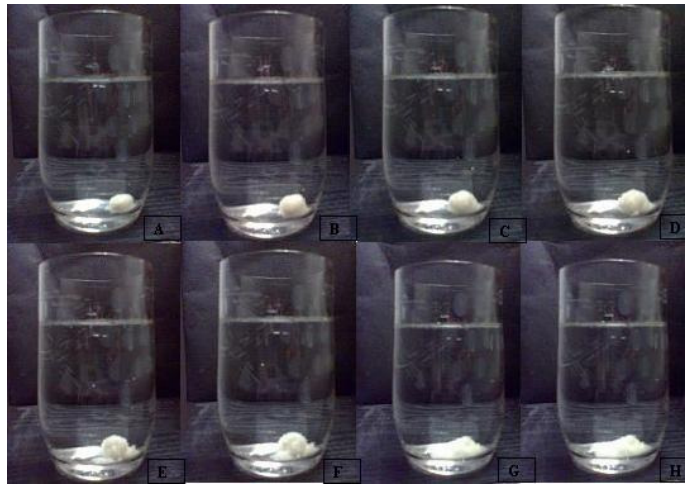

Figure 1: Sequential disintegration of orodispersible tablets of meloxicam $(A=0 \mathrm{sec} ; B=5 \mathrm{sec} ; C$ $=10 \mathrm{sec} ; D=15 \mathrm{sec} ; E=20 \mathrm{sec} ; F=25 \mathrm{sec} ; G=30$ $\mathrm{sec} ; \mathrm{H}=40 \mathrm{sec}$ )

absorption ratio was calculated using Eq. $2^{10}$ :

Water absorption ratio $=\left(W_{a}-W_{b}\right) / W_{b}$

where $W_{b}=$ weight of tablet before absorption of water, and $\mathrm{W}_{\mathrm{a}}=$ weight of tablet after absorption of water.

\section{In vitro drug release}

In vitro drug release studies were carried out using USP type II apparatus at $50 \mathrm{rpm}$. Phosphate buffer $(900 \mathrm{ml})$ at $\mathrm{pH} \quad 6.41$ (corresponding to salivary $\mathrm{pH}$ ) was used as the dissolution medium. The temperature of the dissolution medium was maintained at 37 $\pm 0.5{ }^{\circ} \mathrm{C}$. An aliqout $(5 \mathrm{ml})$ of dissolution medium was withdrawn at specific time intervals, filtered and suitably diluted prior to spectrophotometric analysis. Sink conditions were maintained by replenishing the medium with an equal amount $(5 \mathrm{ml})$ of dissolution fluid. Absorption of the solution was measured by UV spectroscopy (Shimadzu-1700, Japan) at $354 \mathrm{~nm}$. Dissolution rate was evaluated for all the formulations $\left(\mathrm{F}_{1}-\mathrm{F}_{4}\right)$ and the conventional tablet.

\section{Validation of the experimental design}

In order to validate the experimental design using polynomial equation, disintegration time was selected. A two-level experimental design provides sufficient data to fit a polynomial equation $^{11}$ (Eq. 3) which is in the following form:

$$
\mathrm{y}=\mathrm{B}_{0}+\mathrm{B}_{1} \mathrm{X}_{1}+\mathrm{B}_{2} \mathrm{X}_{2}+\mathrm{B}_{12}\left(\mathrm{X}_{1} \mathrm{X}_{2}\right)
$$

where $y$ represents the experimental response, $B_{0}$ the intercept and $B_{1}$ to $B_{12}$ are the coefficients for the factors $X_{1}$ (crospovidone) and $X_{2}$ (mannitol). Students $t-$ test was employed to examine the probability of each coefficient being equal to zero. All tests were performed at a $95 \%$ confidence level $(P>0.05)$. In the final model equation, only the significant factors were included. The polynomial equation was applied to the response parameter, disintegration time, using a software (New Statistica 10v, USA).

\section{Results}

The results of the measurements of various tablet parameters are tabulated in Table 3.

\section{Weight variation and friability}

The weight range was $98-99 \mathrm{mg}$ for all the tablets. This complies with Indian Pharmacopoeia $^{12}$ specifications for uniformity of weight, thus indicating consistency in the preparation of the tablets and minimal batch to batch variation. The India Pharmacopoeia prescribes a friability $<1 \%$ for good mechanical resistance. All the tablet formulations satisfied this requirement as friability was in the range of $0.51-0.69 \%$

\section{Disintegration time}

All the formulations complied with the dispersion time requirement of $\leq 60 \mathrm{sec}$ for orodispersible tablets as per European Pharmacopoeia $^{13}$. Formulation $F_{4}$ had the least dispersion time of $32.1 \mathrm{sec}$ (Table 3). 
Singh \& Singh

Table 3: Physical properties of orodispersible tablets of meloxicam

\begin{tabular}{lllll}
\hline Parameter & \multicolumn{4}{c}{ Formulation } \\
\cline { 2 - 5 } & \multicolumn{1}{c}{$\mathrm{F}_{1}$} & \multicolumn{1}{c}{$\mathrm{F}_{2}$} & \multicolumn{1}{c}{$\mathrm{F}_{3}$} & \multicolumn{1}{c}{$\mathrm{F}_{4}$} \\
\hline Weight Variation $(\mathrm{mg})$ & $98 \pm 0.0$ & $99 \pm 1.3$ & $99 \pm 0.8$ & $98 \pm 0.9$ \\
Friability (\%) & 0.7 & 0.6 & 0.7 & 0.5 \\
Disintegration time (sec) & $33.0 \pm 1.4$ & $34.5 \pm 0.8$ & $34.8 \pm 1.5$ & $32.1 \pm 1.1$ \\
Crushing strength (kg/sqcm) & $4.54 \pm 1.1$ & $4.8 \pm 0.1$ & $4.32 \pm 0.5$ & $4.9 \pm 0.6$ \\
Drug content (\%) & 97.9 & 97.1 & 98.8 & 98.5 \\
Wetting time (sec) & 6.9 & 7.5 & 7.0 & 5.2 \\
Water absorption ratio & 1.1 & 1.0 & 0.9 & 1.5 \\
\hline
\end{tabular}

${ }^{*}$ Value represents a mean of 3 determinations

\section{Crushing strength}

The hardness of the formulated tablets was in the range of $4.54-4.93 \mathrm{~kg} / \mathrm{cm}^{2}$ and did not show any significant difference among the various formulations.

\section{Wetting time and water absorption ratio}

The wetting time of all the tablet formulations was within the range of $5.15-7.50 \mathrm{sec}$ and this indicates rapid absorption of water by the tablets due to the wicking action of crosspovidone. The water absorption of formulation $\mathrm{F}_{4}$ was highest with a value of 1.5 , indicating a high amount of water uptake due to the high concentration of the independent factors.

\section{In vitro drug release}

All the formulations showed optimized drug release, with $98 \%-99 \%$ of the drug released within $30 \mathrm{~min}$.

\section{Validation of the experimental design}

The theoretical response obtained from the polynomial equation at $\mathrm{Y}_{50 \%}$ was found to be $37.22 \mathrm{sec}$ and the experimental response of the extra design point formulation was found to be $34.6 \mathrm{sec} \pm 0.43$ which was quite close to the theoretical response.

\section{Discussion}

Since mannitol has good aqueous solubility, negative heats of solution and good wetting properties, these attributes improve the binding of the tablets and water uptake, thereby decreasing disintegration time. All the formulations disintegrated in less than $60 \mathrm{sec}$. Formulation $\mathrm{F}_{4}$ demonstrated a minimum dispersion time of $32.1 \mathrm{sec}$; in this formulation, mannitol (an orodispersion aid) and crosspovidone were at their highest levels. The in vitro disintegration behavior, without agitation, of formulation $\mathrm{F}_{4}$ indicate that complete dispersion was obtained within 40 $\mathrm{sec}$ (Figure 1). The difference between this value and the disintegration time obtained by the previous method may be attributed to the agitation involved in the previous method. There was no significant difference $(P<0.05)$ among the four tablet formulations $\left(F_{1}-F_{4}\right)$ in terms of their physicochemical properties disintegration time, crushing strength, friability and wetting time - except for water absorption ratio where $\mathrm{F}_{4}$ clearly showed a higher value than the other tablet formulations. The crushing strength values of $4.54-4.93 \mathrm{~kg} / \mathrm{cm}^{2}$ are satisfactory and may have been facilitated by the incorporation of $2 \% \mathrm{w} / \mathrm{w}$ colloidal silicon dioxide which improves the hardness of the tablets, since colloidal silicon dioxide is known to enhance the bonding property of excipients ${ }^{14}$. This also would have had a positive effect on the friability of the tablets as 


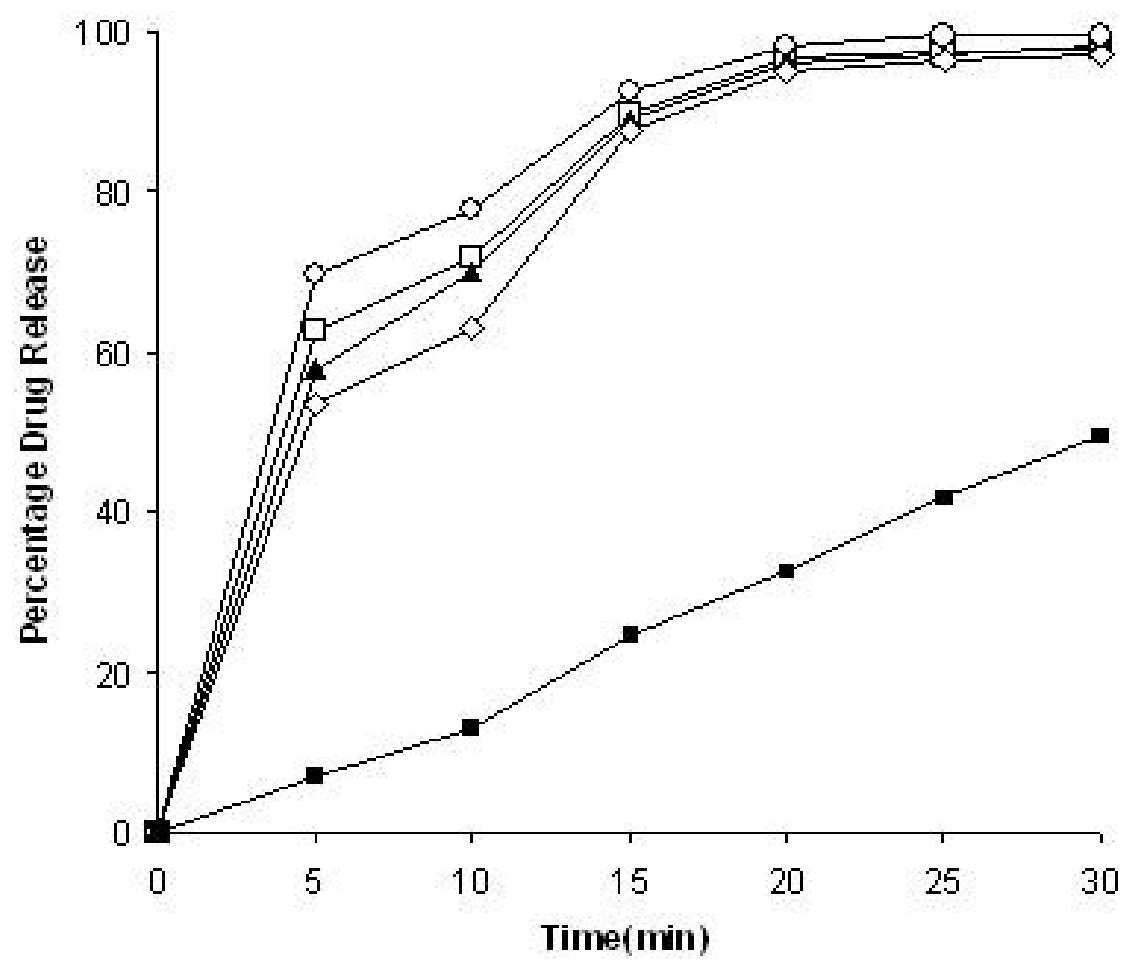

Figure 2: Drug release profile of formulations F1 - F4 and conventional meloxicam tablet in phosphate

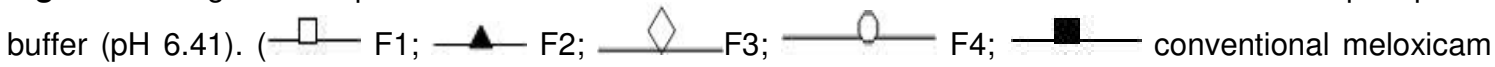
tablet)

friability was within the limit of $1 \%$. The water uptake ratio of $\mathrm{F}_{4}$ tablets was 1.521 times its actual weight, thus facilitating the process of orodispersion.

All the formulations showed good drug release which was in the range, $98 \%-99 \%$, after 30 min. Thus, incorporation of varying concentrations of crospovidone and mannitol did not significantly alter drug release (Figure 2). However, conventional meloxicam tablets exhibited approximately $50 \%$ of the release rate of the optimized tablets $\left(F_{1}-F_{4}\right)$. The formulation followed first order kinetics as a linear plot was obtained when log drug release was plotted against time. The correlation coefficient of the plot was 0.9792 . The disintegration time data can be described by a model equation (Eq 4):
$\mathrm{Y}_{\text {disintegration time }}=28.91+1.21\left(\mathrm{X}_{1}\right)+2.48\left(\mathrm{X}_{2}\right)$ $+4.62\left(\mathrm{X}_{1} \mathrm{X}_{2}\right)$

The positive coefficient for equation $X_{1}$ indicates that a higher level of crosspovidone in the tablet formulation facilitated disintegration. The theoretical response at $Y_{50 \%}$ was $37.22 \mathrm{sec}$ while the experimental response of the extra design point formulation was $34.6 \mathrm{sec} \pm 0.43$ which was quite close to the theoretical response, thus validating the experimental design.

\section{Conclusion}

All the optimized tablet (orodispersible) formulations $\left(F_{1}-F_{4}\right)$ showed disintegration times that were less than $60 \mathrm{sec}$, as well as good physicochemical properties. Drug release rates of the orodispersable tablets 
were much higher than that of the conventional tablets. The experimental design was also validated, as the theoretical response obtained correlated well with the practical response. The results indicate that the presence of crospovidone and mannitol not only enhanced the rate of orodispersion but also improved drug release rate. Thus, satisfactory orodispersible tablets of meloxicam for large-scale production is feasible.

\section{References}

1. Bi Y, Sunada H, Danjo K, Otsuka A. Preparation and evaluation of a compressed tablet rapidly disintegrating in the oral cavity. Chem. Pharm. Bull. 1996; 44: 2121-2127.

2. Bi $Y$, Sunada H, Danjo K, Yonezawa Y. Evaluation of rapidly disintegrating tablets prepared by a direct compression method. Drug Dev. Ind. Pharm. 1999; 25: 571-581.

3. Goodman GA. The Pharmacological Basis of Therapeutics. New York, USA, McGraw-Hill Inc., 1997, pp 447-448.

4. Kornblum S, Stopak S. A new tablet disintegrating agent: Crosslinked polyvinyl pyrrolidone. J Am Pharm Assoc, 2001; 41(2): 229-272.
5. British Pharmacopoeia, vol. I, Great Britain, Directorate of Medicine and Health; 2004. pp 1042-1045.

6. Bolton S. Pharmaceutical statistics In: Drug and the Pharmaceutical Sciences. New York, USA, Marcel Decker Inc, 1997, pp 326-338

7. Indian Pharmacopoeia, Controller of Publications, New Delhi, $4^{\text {th }}$ edition, vol II, 1996, Appendices 7-8.

8. Indian Pharmacopoeia, Controller of Publications, New Delhi, $4^{\text {th }}$ edition, vol II, 1996, pp 234-236.

9. Bi Y, Akinobu O. Evaluation of a compressed tablet rapidly disintegrating in the oral cavity. Chem. Pharm. Bull. 1995; 44: 2011-2017.

10. Gohel MC, Bhatt N. Formulation and evaluation of orodispersible taste masked tablets of famotidine. Pharma. Bio. World. 2005; 75-79 .

11. Bolton S. Pharmaceutical Statistics In: Drug and the Pharmaceutical Sciences, New York,USA, Marcel Decker Inc;1997, pp 345-351.

12. Indian Pharmacopoeia, Controller of Publications, New Delhi, $4^{\text {th }}$ edition, volll,1996, pp 735-736.

13. European Pharmacopoeia, Directorate of Medicine and Health, Great Britain, $5^{\text {th }}$ edition, vol I, 2005, pp 628-629.

14. Sallam E, Khalil E. Tablets quickly disintegrating in the oral cavity and process for producing the same. Drug Dev. Ind. Pharm. 1998; 24: 501 507. 